\title{
Synergistic Antimicrobial Effect of Raspberry (Rubus idaeus L., Rosaceae) Preparations and Probiotic Bacteria on Enteric Pathogens
}

\author{
Justyna Bauza-Kaszewska ${ }^{1 *}\left({ }^{\oplus}\right.$, Ewa Żary-Sikorska ${ }^{1}{ }^{\oplus}$, Andrzej Gugolek $^{2}{ }^{\oplus}$, Anna Ligocka $^{1}{ }^{\oplus}$,

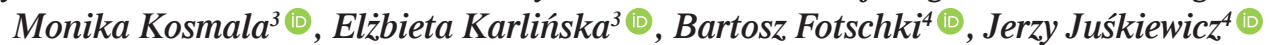 \\ ${ }^{I}$ Department of Microbiology and Food Technology, Faculty of Agriculture and Biotechnology, \\ University of Science and Technology, Kaliskiego 7, 85-796 Bydgoszcz, Poland \\ ${ }^{2}$ Department of Fur-bearing Animal Breeding and Game Management, Faculty of Animal Bioengineering, \\ University of Warmia and Mazury in Olsztyn, Oczapowskiego 5, 10-718 Olsztyn, Poland \\ ${ }^{3}$ Institute of Food Technology and Analysis, Eódź University of Technology, Stefanowskiego 4/10, 90-924 Łódź, Poland \\ ${ }^{4}$ Department of Biological Functions of Food, \\ Institute of Animal Reproduction and Food Research of the Polish Academy of Sciences, Tuwima 10, 10-748 Olsztyn, Poland
}

Key words: raspberry, bioactive compounds, antimicrobial properties, pathogenic bacteria, probiotic Lactobacillus

Due to the increasing microbial tolerance to commonly used food preservatives, as well as growing consumer awareness of their adverse impact on human health, alternative methods of pathogens reduction in food are widely investigated. The aim of this research was to examine the antimicrobial activity of red raspberry pomace and seed preparations against enterohemorrhagic Escherichia coli (EHEC), Salmonella Typhimurium, Salmonella Enteritidis, Listeria monocytogenes, and probiotic Lactobacillus rhamnosus strain. The combined action of LAB (lactic acid bacteria) and raspberry preparations on the pathogenic species was also evaluated. The results of our study showed no or weak antibacterial effect of raspberry preparations on the pathogenic bacteria tested. Regardless of preparation concentration ( 1.0 or $2.0 \mathrm{mg} / \mathrm{mL}$ ), the bacteria number after 48 -h incubation was usually higher than in the culture at the initial stage and varied from $10^{5}$ to $10^{7} \mathrm{cfu} / \mathrm{mL}$. On the other hand, probiotic Lactobacillus rhamnosus strain caused a significant reduction in the enteric pathogen count after 24-h co-culture with LAB. The concentrations of both Salmonella serotypes were below the detection limit of the analytical methods applied. Moreover, the combined use of LAB and raspberry preparations resulted in the total elimination of Salmonella strains and the reduction in L. monocytogenes number from $10^{5}$ to $10^{2}-10^{4} \mathrm{cfu} / \mathrm{mL}$ after $24-\mathrm{h}$ co-culture. EHEC revealed the highest resistance to the mixed culture effect. The synergic antimicrobial effect suggests the possibility of applying probiotic bacteria and berry preparations as natural antimicrobial agents in the food industry.

\section{INTRODUCTION}

Microbiological contamination of food is of great concern for the food industry. A considerable number of foodborne pathogens linked to serious illness and foodborne outbreaks (e.g. Salmonella spp., EHEC, Listeria monocytogenes, Campylobacter jejuni) have recently gained an intense attention of epidemiologists. There are various types of preservatives used to minimize the risk related to foodborne infections. However, due to the high prevalence of antibiotic-resistant microorganisms in food, increasing microbial tolerance to conventional food preservation methods is observed. Moreover, common consumer awareness of the adverse impact of chemicals on human health prompts a growing interest in the potential use of natural preservatives.

Natural preservatives of different origins; e.g. animal, plant, and microbiological; have been widely studied and

\footnotetext{
* Corresponding Author: Tel.: +48 5237495 35; Fax: +48 5237495 05; E-mail: bauza@utp.edu.pl (J. Bauza-Kaszewska)
}

their antimicrobial effectiveness remains undoubtful [Baptista et al., 2020; Harich et al., 2018; Salaheen et al., 2016]. Their plant-derived representatives show direct antibacterial effects on the growth and metabolism of microorganisms or may indirectly modify their antibiotic resistance [Stefanovic et al., 2012]. The application of essential oils and plant extracts as preservatives usually provides additional health benefits associated with the presence of specific active substances in their composition. The group of particular importance are phenolics, revealing high antibacterial and antifungal properties [Negi, 2012; Pandey et al., 2017].

Fruits of red raspberry (Rubus ideaus L.), one of the most popular berry crops in the world, are commonly consumed both as fresh and as ingredients in processed food products. They are a rich source of various bioactive phenolic compounds, among which anthocyanins, ellagitannins, and conjugates of ellagic acid and quercetin are of great significance [Burton-Freeman et al., 2016; Klewicka et al., 2016; Stój et al., 2006]. The total phenolic content of red raspberries varies from 200 to $500 \mathrm{mg} / 100 \mathrm{~g}$ of fresh matter; however, 
the content of anthocyanins varies between cultivars [Grumezescu, 2016; Simmonds \& Preedy, 2015]. Among the anthocyanins found in red raspberries, cyanidin 3-O-sophoroside, cyanidin 3-O-glucoside, and pelargonidin 3-O-sophoroside are the most common and account for $79.8 \%, 14.2 \%$, and $6.0 \%$ of the total anthocyanin content, respectively [Coultate, 2016; Shahidi \& Alasalvar, 2016]. Sanguiin H-6 and lambertianin $\mathrm{C}$ are the major raspberry ellagitannins; however, their content and profile are genetically-determined and vary among different raspberry cultivars [Klewicka et al., 2016; Vrhovsek et al., 2009].

Fresh raspberries are the best source of bioactive compounds. Due to the short harvesting period, fresh raspberry fruits are mostly frozen or processed into concentrate, preserves, canned products, aseptic packs, and juice. During industrial juice production, a significant amount of the biologically-active ingredients remains in the fruit pomace and seeds [Schieber et al., 2001]. These processed products still contain valuable substances and, therefore, increase the bio-potential of the by-products [Balasundram et al., 2006]. The profiles of their phenolic compounds are similar to fresh fruits but the phenolic content of seeds and pomace is lower than that of fruit. Although anthocyanins in raspberries are quantitatively the most important polyphenols, they are accumulated mostly in the flesh and transferred to juice in the process of its production, which is why they are found in little quantities in the seeds and pomace. Contrary to the anthocyanins, ellagitannins accumulate mainly in the pomace. It should be emphasized that $80 \%$ of the dried raspberry pomace consists of the seeds. The fine grinding of the native pomace results in the damage to the seed coat, increasing the availability of the accumulated valuable seed compounds [Fotschki et al., 2017].

Besides their beneficial effect on human health [Jimenez-Garcia et al., 2013; Paredes-López et al., 2010], phytochemicals in red raspberries show antimicrobial activity against many human pathogens [Nile \&Park, 2014]. The complex phenolic polymers, such as ellagitannins, are particularly active in this respect [Heinonen, 2007; Małecka et al., 2003]. The results of many research suggest various mechanisms related to the pathogen growth inhibition by berry phenolics, e.g. disruption of cytoplasmic membrane structure, permeabilization of the cell membrane, inhibition of extracellular enzyme secretion, or direct effect on microbial metabolism processes [Puupponen-Pimiä et al., 2005a]. Since the colonization of intestinal epithelium is crucial for the food-borne bacterial infections, the anti-adherence activity of active substances in berries is also linked to their antimicrobial effect [Das et al., 2017; Puupponen-Pimiä et al., 2005b].

Among the natural substances used as natural food preservatives, lactic acid bacteria (LAB) metabolites demonstrate great antimicrobial potential [Adetoye et al., 2018]. Organic acids, hydrogen peroxide, and bacteriocins inhibit the growth of intestinal and food-borne pathogens [Chen et al., 2019].

Due to the antibacterial features of both, LAB and raspberry active substances (phenolic compounds), the putative synergic action of their combination, increasing the beneficial effect on human health, can be presumed. In this context, the co-application of these biocomponents in functional food (fermented milk products, juices) is an issue of a special interest.
The aim of this study was to investigate the antibacterial effects of dried preparations obtained from raspberry pomace, seed, and seedless pomace after industrial juice production against enterohemorrhagic E. coli (EHEC), Salmonella Typhimurium, Salmonella Enteritidis, Listeria monocytogenes, and probiotic Lactobacillus rhamnosus strain. The synergistic effect of LAB and raspberry preparations on the pathogenic species was also examined.

\section{MATERIALS AND METHODS}

\section{Raspberry preparations}

Native raspberry ( $R$. ideaus) pomace (preparation $\mathrm{P}$ ), seed preparation (preparation $\mathrm{S} ;>95 \%$ seed content), and raspberry seedless pomace (preparation $\mathrm{W} ;<5 \%$ seed content) were supplied by Agro-Bio-Produkt Sp. z o.o. (Grodkowice, Poland). The native $\mathrm{P}$ pomace was a biomass residue after industrial juice production and drying in the SB-1.5 rotary drum dryer (AGROMECH Co., Rogozno Wlkp., Poland). The seed preparation was a commercial product intended for high-quality oil production. It was obtained by the producer with the aid of two layers of a mesh screen taking into account the average dimension (length, width, and thickness) of $R$. ideaus seeds. The $\mathrm{W}$ preparation was a residue obtained after the S preparation production. In order to standardize all three preparations, their samples were ground in a cryogenic environment (Freezer Mill 6870 SPEX, SamplePrep. Inc., Stanmore, UK) to obtain particles smaller than $0.65 \mathrm{~mm}$. That process made it possible to get through the seed coat and to preserve the bioactive components on the preparations.

\section{Proximate composition of the preparations}

The official methods of the Association of Official Analytical Chemists [AOAC, 2007] method were used to determine the proximate analysis of the raspberry preparations: protein content, 920.152; dry $\mathrm{m}$ atter and ash content, 940.26; ether extract, 930.09; total dietary fiber (TDF) content, 985.29, and insoluble dietary fiber (IDF) content, 991.42. The soluble dietary fiber (SDF) content was estimated as the difference between TDF and IDF content. All analyses were performed in triplicate.

\section{Phenolics content of the preparations}

A three-step extraction procedure with acetone-water-formic acid (70:29.9:0.1, $v / v / v)$ was applied to extract phenolics from preparations tested. First, $500 \mathrm{mg}$ of ground material was vortexed with $4 \mathrm{~mL}$ of the solvent. After sonication for $15 \mathrm{~min}$ and centrifugation at 4,800 $\times \mathrm{g}$, the extract obtained was transferred into a flask. The vortexing was repeated twice with $3 \mathrm{~mL}$ of the solvent.

The content of ellagitannins was determined using a Smartline chromatograph (Knauer, Berlin, Germany) with a degasser (Manager 5000), two pumps (P1000), autosampler (3950), thermostat, and photodiode array detector (2800). Ellagitannins were separated on a Gemini C18 column: $250 \times 4.6 \mathrm{~mm}, 5 \mu \mathrm{m}, 110 \AA$ (Phenomenex, Torrance, CA) by gradient elution with solvent A $(0.05 \%[v / v]$ phosphoric acid-water) and solvent B (63:20:17 [v/v/v] acetonitrile-methanol- 
-water with $0.05 \%$ phosphoric acid). The column temperature was set at $35^{\circ} \mathrm{C}$, the flow rate was $1.25 \mathrm{~mL} / \mathrm{min}$, and the gradient program was as follows: $0-5 \mathrm{~min}, 5 \%(\mathrm{v} / \mathrm{v}) \mathrm{B} ; 5-30 \mathrm{~min}$, 5-28\% (v/v) B; 30-40 min, 28-73\% (v/v) B; 40-45 min, 73\% $(v / v) \mathrm{B} ; 45-47 \mathrm{~min}, 73-5 \%(v / v) \mathrm{B}$; and $47-56 \mathrm{~min}, 5 \%(v / v) \mathrm{B}$. The injection volume was $20 \mu \mathrm{L}$.

ClarityChrom v. 3.0.5.505 software (Knauer, Berlin, Germany) was applied for data collection. The standards applied were ellagic acid, sanguiin $\mathrm{H}-6$, lambertianin $\mathrm{C}$, and bis-HHDP-glucose (Extrasynthese, Genay, France).

The excess phloroglucinol degradation method was applied to determine the content of procyanidins. A methanol solution $(0.8 \mathrm{~mL})$ with phloroglucinol $(75 \mathrm{~g} / \mathrm{L})$ and ascorbic acid $(15 \mathrm{~g} / \mathrm{L})$ were added to a $20 \mathrm{mg}$ sample. To start the reaction, $0.4 \mathrm{~mL}$ of $0.2 \mathrm{M}$ hydrochloric acid in methanol were added. The reaction proceeded at $50^{\circ} \mathrm{C}$ for $30 \mathrm{~min}$ and was stopped by adding $0.6 \mathrm{~mL}$ of a $40 \mathrm{mM}$ sodium acetate solution in an ice bath. The samples were centrifuged at $3,600 \times \mathrm{g}$ for $5 \mathrm{~min}$, diluted with a $40 \mathrm{mM}$ sodium acetate solution, and analyzed using a Smartline chromatograph with a P2800 UV-Vis detector (both from Knauer, Berlin, Germany), an RF-10AXL fluorescence detector (FD) (Shimadzu, Tokyo, Japan), and a Gemini C18 column (110 A, $5 \mu \mathrm{m}, 250 \times 4.60 \mathrm{~mm}$ ) (Phenomenex, Torrance, USA). Phase A consisted of acetic acid and water $(2.5: 97.5, v / v)$, while phase B of acetonitrile and water $(80: 20, v / v)$. The applied gradient, with the flow rate of $1 \mathrm{~mL} / \mathrm{min}$ at $25^{\circ} \mathrm{C}$, was as follows: 0-10 $\mathrm{min}, 4-7 \%(v / v) \mathrm{B} ; 10-27 \mathrm{~min}, 7-30 \%(v / v) \mathrm{B}$; 27-29 $\min , 30-70 \%(v / v)$ B; 29-34 min, 70\% (v/v) B; 34-35 min, 7-40\% (v/v) B; and 35-40 min, 4\% (v/v) B. Comparison of the retention times and UV-Vis spectra with those of standards: (-)-epicatechin, (+)-catechin, (-)-epicatechin-phloroglucinol adduct, and $(+)$-catechin-phloroglucinol adduct, was used for identification. The excitation and the emission wavelengths were $278 \mathrm{~nm}$ and $360 \mathrm{~nm}$, respectively.

\section{Microorganisms tested}

The bacterial strains: Salmonella Typhimurium, Salmonella Enteritidis, EHEC, and Listeria monocytogenes from the collection of the Department of Microbiology and Food Technology, UTP University of Science and Technology in Bydgoszcz, Poland, were used in the study. Lactobacillus rhamnosus strain was obtained from a commercial probiotic preparation.

\section{Antimicrobial activity of raspberry preparations}

The liquid culture method was used to study the effect of $\mathrm{P}, \mathrm{W}$, and $\mathrm{S}$ raspberry preparations on the bacteria tested. The liquid growth medium LAPTg $(10 \mathrm{~mL})$ was inoculated with $100 \mu \mathrm{L}$ of a bacterial overnight culture. The initial bacterial culture titer was $10^{8} \mathrm{cfu} / \mathrm{mL}$. Raspberry preparations were suspended in $10 \mathrm{~mL}$ of inoculated media to a final concentration of 1.0 or $2.0 \mathrm{mg} / \mathrm{mL}$. Preparations doses were chosen according to Nohynek et al. [2006] and Puupponen-Pimiä et al. [2001] methodologies. The cultures were incubated at $37^{\circ} \mathrm{C}$ for $48 \mathrm{~h}$. Bacterial culture samples were taken four times during an incubation time - immediately after inoculation (0) and after 6,24 , and $48 \mathrm{~h}$. The samples were diluted by introducing $1 \mathrm{~mL}$ of the culture into test tubes containing sterile $0.9 \%$
$\mathrm{NaCl}$ solution $\left(10^{1}-10^{9}\right)$. Next, $0.1 \mathrm{~mL}$ of each dilution was transferred and distributed on the medium surface, using the spread plate technique. The following selective growth media were used for bacteria isolation: EHEC - Endo Agar (Merck, 1.04044), Salmonella strains - BPL Agar (Merck, 1.10747), L. monocytogenes - ALOA (Merck, 1.00427), and L. rhamnosus - Rogosa Agar (Merck, 1.05413). The incubation of the tested microorganisms was conducted at $37^{\circ} \mathrm{C}$ for $24-48 \mathrm{~h}$. Bacterial cultures with no raspberry preparations were used as controls. Each experiment was performed in triplicate.

\section{Antimicrobial activity of probiotic Lactobacillus strain}

The co-culture (mixed cultures, associated cultures) method was applied to estimate the interaction between L. rhamnosus and pathogenic strains. Co-cultures were obtained by adding $100 \mu \mathrm{L}$ of a $24-\mathrm{h} L$. rhamnosus pure culture and $100 \mu \mathrm{L}$ of an individual pathogen pure culture to $10 \mathrm{~mL}$ of the liquid growth medium LAPTg. The initial titer of both bacterial cultures was $10^{8} \mathrm{cfu} / \mathrm{mL}$. To examine the effect of $\mathrm{LAB}$ on the pathogens tested, the co-cultures were incubated at $37^{\circ} \mathrm{C}$ for $24 \mathrm{~h}$. Culture samples were taken five times during the incubation time - immediately after inoculation (0) and after 15, 18, 21 , and $24 \mathrm{~h}$. The samples were diluted by introducing $1 \mathrm{~mL}$ of the culture into test tubes containing sterile $0.9 \% \mathrm{NaCl}$ solution $\left(10^{1}-10^{9}\right)$. Then, $0.1 \mathrm{~mL}$ of each dilution was plated out by spread plating on different selective solid media, allowing the growth of only one of the two microorganisms composing the mix. The cultures were incubated at $37^{\circ} \mathrm{C}$ for $24-48 \mathrm{~h}$. Pure cultures of each bacteria were used as controls. The selective media and incubation conditions were similar to those described above. Each experiment was performed in triplicate.

\section{Evaluation of the synergistic effect of raspberry preparations and Lactobacillus on the pathogens tested}

Co-cultures of individual pathogenic bacterial strains and L. rhamnosus, enriched with raspberry preparations, were used to assess the combined action of LAB and raspberry compounds. The liquid growth medium LAPTg $(10 \mathrm{~mL})$ was inoculated with $100 \mu \mathrm{L}$ of the L. rhamnosus overnight culture and $100 \mu \mathrm{L}$ of the pathogen overnight culture. The initial titer of both bacterial cultures was $10^{8} \mathrm{cfu} / \mathrm{mL}$. Then, raspberry preparations were added to the inoculated media to a final concentration of $2.0 \mathrm{mg} / \mathrm{mL}$. The co-cultures were incubated at $37^{\circ} \mathrm{C}$ for $24 \mathrm{~h}$. Culture samples were taken five times during the incubation time - immediately after inoculation (0) and after $15,18,21$, and $24 \mathrm{~h}$. The samples were diluted by introducing $1 \mathrm{~mL}$ of the culture into test tubes containing sterile $0.9 \% \mathrm{NaCl}$ solution $\left(10^{1}-10^{9}\right)$. Then, $0.1 \mathrm{~mL}$ of each dilution was plated out by spread plating on the growth media as described above. The tested microorganisms were incubated at $37^{\circ} \mathrm{C}$ for $24-48 \mathrm{~h}$. Pure cultures of each bacteria were used as controls. Each experiment was performed in triplicate.

\section{Statistical analysis}

Statistical analysis was performed using Statistica software (TIBCO Software Inc., Palo Alto, CA, USA). The results are presented as mean \pm standard deviation (SD). Differences between control and experimental variants were analyzed by one-way ANOVA followed by the Dunnett's test $(\mathrm{p}<0.05)$. 


\section{RESULTS AND DISCUSSION}

The chemical composition of raspberry preparations is summarized in Table 1. The content of total phenolics in raspberry preparations varied from $1665 \mathrm{mg} / 100 \mathrm{~g}$ in seed preparation (S) to $4253 \mathrm{mg} / 100 \mathrm{~g}$ in seedless pomace (W). The highest content of ellagitannins (4020 mg/100 g) was also noted in the seedless pomace preparation (W) (Table 1). Klimczak et al. [2011] demonstrated that most of the phenolics accumulate in the seedless fraction of the pomace; consequently, an increased concentration of these bioactive compounds was observed after the removal of seeds from the raspberry pulp.

All of the three preparations tested (W, S, P) showed no or low antimicrobial effect on the microorganisms tested, and bacterial species did not affect the raspberry inhibitory efficiency (Table 2). According to Nohynek et al. [2006], different bacterial species and strains demonstrate variable sensitivity to phenolic berry extracts. The results of their research showed a high efficiency of raspberry against Helicobacter pylori and Bacillus cereus. Growth inhibition of Campylobacter jejuni and Candida albicans was linked to the high content of ellagitannins in the composition of the tested extracts [Nohynek et al., 2006]. In turn, Puupponen-Pimiä et al. [2001, 2005a] reported a low antimicrobial activity of raspberry against Gram-positive bacteria, including L. monocytogenes. On the other hand, raspberry extracts were strong inhibitors of Gram-negative intestinal bacteria, which might be the effect of different cell membrane structure. These findings were not confirmed by Velićanski et al. [2012], who reported a higher, compared to G-positive, resistance of G-negative bacteria, especially with Escherichia coli and Salmonella Typhimurium to raspberry pomace extracts in agar diffusion tests. Among all G-positive bacteria tested, L. monocytogenes showed the lowest sensitivity. Similarly, the study of Krstic et al. [2014] demonstrated the antibacterial activity of the raspberry ethanol extract and juice on Gram-positive bacteria. Rauha et al. [2000] observed that the inhibitory action of raspberry phenolics on bacteria tested was not limited to G-positive and G-negative species only. The raspberry active compounds inhibited the growth of Bacillus subtilis and Micrococcus luteus but had only limited effect on E. coli, Pseudomonas aeruginosa, Staphylococcus aureus, and Staphylococcus epidermidis. The results of a study by Četojević-Simin et al. [2015] showed that Gram-positive and Gram-negative bacteria were similarly susceptible to raspberry pomace extracts, and that the growth inhibition of various bacterial species was neither strain- nor species-dependent.

Various internal and external factors might have caused the low antibacterial activity of the tested raspberry products in our study. The berry cultivar, as well as the procedure applied to obtain the plant preparations, influence the amount and composition of phenolic compounds and the antimicrobial action of a final product [Krisch et al., 2008; Krstic et al., 2014; Lima et al., 2019]. The antibacterial efficiency of berry preparations is also due to their concentration applied in the experimental procedure. The doses used in our study were 1.0 or $2.0 \mathrm{mg} / \mathrm{mL}$. Nohynek et al. [2006] observed 0.5 to $1.5 \log$ reduction of $C$. jejuni number after 5-h incubation with lyophilized raspberry extracts in a $1.0 \mathrm{mg} / \mathrm{mL}$ concentration. A similar dose of raspberry extracts totally inhibited the growth of
TABLE 1. Chemical composition of raspberry pomace and seed preparations.

\begin{tabular}{|c|c|c|c|}
\hline Content & $\begin{array}{l}\text { Native } \\
\text { pomace } \\
(\mathrm{P})\end{array}$ & $\begin{array}{c}\text { Seedless } \\
\text { pomace } \\
(\mathrm{W})\end{array}$ & $\begin{array}{l}\text { Seeds } \\
\text { (S) }\end{array}$ \\
\hline Dry matter $(\mathrm{g} / 100 \mathrm{~g})$ & $95.4 \pm 0.0$ & $95.3 \pm 0.0$ & $96.5 \pm 0.2$ \\
\hline Ash $(\mathrm{g} / 100 \mathrm{~g})$ & $2.68 \pm 0.25$ & $5.12 \pm 0.02$ & $1.71 \pm 0.06$ \\
\hline Protein $(\mathrm{g} / 100 \mathrm{~g})$ & $11.4 \pm 0.0$ & $18.9 \pm 0.1$ & $10.5 \pm 0.5$ \\
\hline Ether extract $(\mathrm{g} / 100 \mathrm{~g})$ & $12.2 \pm 0.1$ & $6.00 \pm 0.01$ & $14.1 \pm 0.2$ \\
\hline TDF (g/100 g), including: & $61.3 \pm 0.7$ & $54.3 \pm 0.5$ & $63.9 \pm 0.4$ \\
\hline IDF $(g / 100 \mathrm{~g})$ & $59.2 \pm 0.7$ & $51.4 \pm 0.5$ & $62.7 \pm 0.4$ \\
\hline $\mathrm{SDF}(\mathrm{g} / 100 \mathrm{~g})$ & $2.12 \pm 0.06$ & $2.90 \pm 0.07$ & $1.23 \pm 0.02$ \\
\hline $\begin{array}{l}\text { Total phenolics } \\
\text { (mg/100 g), including: }\end{array}$ & $2359 \pm 30$ & $4253 \pm 23$ & $1665 \pm 44$ \\
\hline Ellagitannins & $1949 \pm 18$ & $4020 \pm 12$ & $1211 \pm 34$ \\
\hline bis-HHDP-glucoseisomer 1 & $36.5 \pm 4.0$ & $32.7 \pm 2.2$ & $34.6 \pm 3.2$ \\
\hline bis-HHDP-glucoseisomer 2 & $41.8 \pm 2.1$ & $3.40 \pm 0.30$ & $38.9 \pm 2.4$ \\
\hline Sanguiin H10 isomer 1 & $34.0 \pm 0.1$ & $43.8 \pm 0.6$ & $31.8 \pm 0.5$ \\
\hline $\begin{array}{l}\text { Lambertianin } \mathrm{C} \\
\text { without ellagic acid }\end{array}$ & $44.9 \pm 0.9$ & $84.8 \pm 0.5$ & $29.1 \pm 1.4$ \\
\hline SanguiinH10 isomer 2 & $0.0 \pm 0.0$ & $65.0 \pm 1.0$ & $31.1 \pm 1.0$ \\
\hline Lambertianin $\mathrm{C}$ isomer 1 & $17.0 \pm 0.8$ & $25.9 \pm 1.4$ & $21.5 \pm 0.7$ \\
\hline Lambertianin $\mathrm{C}$ isomer 2 & $56.4 \pm 0.0$ & $75.7 \pm 1.0$ & $41.9 \pm 0.0$ \\
\hline Lambertianin $\mathrm{C}$ isomer 3 & $53.5 \pm 4.0$ & $142 \pm 6$ & $14.4 \pm 0.8$ \\
\hline Lambertianin D & $92.3 \pm 1.5$ & $226 \pm 3$ & $113 \pm 3$ \\
\hline Lambertianin $\mathrm{C}$ & $820 \pm 8$ & $1998 \pm 0$ & $375 \pm 7$ \\
\hline Sanguiin-H6 & $752 \pm 5$ & $1322 \pm 1$ & $478 \pm 15$ \\
\hline Ellagic acid & $73.4 \pm 1.0$ & $139 \pm 1$ & $106 \pm 5$ \\
\hline Procyanidins & $397 \pm 12$ & $229 \pm 11$ & $439 \pm 9$ \\
\hline Free catechins & $13.1 \pm 0.1$ & $3.40 \pm 0.04$ & $14.9 \pm 0.5$ \\
\hline
\end{tabular}

TDF - total dietary fiber; IDF - insoluble dietary fiber; SDF - soluble dietary fiber.

S. Typhimurium and E. coli CM 871 and decreased the number of $E$. coli strain 50 by $2 \operatorname{logs}$, compared to the control culture [Puupponen-Pimiä et al., 2001]. Puupponen-Pimiä et al. [2005a] noted a strong inhibitory effect of raspberry extracts at a low concentration $(1.0 \mathrm{mg} / \mathrm{mL})$ at the initial phase of Salmonella strains cultivation, followed, however, by the increase in bacteria number after 12 and $24 \mathrm{~h}$ of incubation. Application of the $5.0 \mathrm{mg} / \mathrm{mL}$ dose resulted in the complete elimination of $S$. Typhimurium after 2-h incubation. In our study, the effect of raspberry preparations on pathogenic bacteria was dose-independent. The number of the microorganisms tested in the initial culture varied from $10^{4}$ to $10^{7} \mathrm{cfu} / \mathrm{mL}$ and, in the majority of experimental variants, increased after 6 and $24 \mathrm{~h}$ of incubation. During the next $24 \mathrm{~h}$, a slight reduction was observed in bacteria culture density; however, the cell count was usually higher than in the culture at the initial stage (Table 2). 
TABLE 2. Effect of raspberry preparations on the bacteria count $(\mathrm{cfu} / \mathrm{mL})$.

\begin{tabular}{|c|c|c|c|c|c|c|}
\hline \multirow{2}{*}{ Microorganism } & \multirow{2}{*}{\multicolumn{2}{|c|}{$\begin{array}{l}\text { Preparation dose } \\
\text { and type }\end{array}$}} & \multicolumn{4}{|c|}{ Incubation time $(\mathrm{h})$} \\
\hline & & & 0 & 6 & 24 & 48 \\
\hline \multirow{7}{*}{ EHEC } & & W & $3.20 \times 10^{6} \pm 1.44 \times 10^{6}$ & $4.00 \times 10^{8} \pm 2.65 \times 10^{7}$ & $2.80 \times 10^{8} \pm 7.55 \times 10^{7}$ & $7.67 \times 10^{7} \pm 1.53 \times 10^{7^{*}}$ \\
\hline & $1 \mathrm{mg} / \mathrm{mL}$ & $\mathrm{S}$ & $3.00 \times 10^{6} \pm 7.00 \times 10^{5}$ & $3.47 \times 10^{8} \pm 1.26 \times 10^{8}$ & $4.43 \times 10^{8} \pm 9.81 \times 10^{7}$ & $5.53 \times 10^{7} \pm 3.00 \times 10^{7}$ \\
\hline & & $\mathrm{P}$ & $3.73 \times 10^{6} \pm 9.29 \times 10^{5}$ & $3.43 \times 10^{8} \pm 5.77 \times 10^{7}$ & $3.30 \times 10^{8} \pm 1.15 \times 10^{8}$ & $4.13 \times 10^{7} \pm 1.69 \times 10^{7}$ \\
\hline & & W & $4.00 \times 10^{6} \pm 7.00 \times 10^{5^{*}}$ & $3.37 \times 10^{8} \pm 2.08 \times 10^{7}$ & $1.80 \times 10^{8} \pm 7.21 \times 10^{7}$ & $1.18 \times 10^{8} \pm 3.05 \times 10^{6^{*}}$ \\
\hline & $2 \mathrm{mg} / \mathrm{mL}$ & S & $4.83 \times 10^{6} \pm 1.25 \times 10^{6^{6}}$ & $5.13 \times 10^{8} \pm 2.27 \times 10^{8}$ & $2.63 \times 10^{8} \pm 2.89 \times 10^{7}$ & $9.03 \times 10^{7} \pm 2.87 \times 10^{7^{*}}$ \\
\hline & & $\mathrm{P}$ & $6.40 \times 10^{6} \pm 4.58 \times 10^{5^{5}}$ & $2.63 \times 10^{8} \pm 5.77 \times 10^{6}$ & $2.13 \times 10^{8} \pm 7.64 \times 10^{7}$ & $7.50 \times 10^{7} \pm 1.51 \times 10^{7^{*}}$ \\
\hline & Cont & & $1.90 \times 10^{6} \pm 1.00 \times 10^{5}$ & nd & nd & $1.50 \times 10^{7} \pm 1.30 \times 10^{7}$ \\
\hline \multirow{7}{*}{$\begin{array}{l}\text { Listeria } \\
\text { monocytogenes }\end{array}$} & & W & $7.53 \times 10^{5} \pm 1.74 \times 10^{5^{*}}$ & $6.83 \times 10^{6} \pm 1.07 \times 10^{6}$ & $7.93 \times 10^{5} \pm 2.00 \times 10^{5}$ & $4.43 \times 10^{7} \pm 6.03 \times 10^{6^{*}}$ \\
\hline & $1 \mathrm{mg} / \mathrm{mL}$ & S & $7.27 \times 10^{5} \pm 3.05 \times 10^{4^{*}}$ & $2.60 \times 10^{5} \pm 3.46 \times 10^{4}$ & $8.83 \times 10^{5} \pm 2.75 \times 10^{5}$ & $5.43 \times 10^{7} \pm 2.08 \times 10^{6^{*}}$ \\
\hline & & $\mathrm{P}$ & $6.67 \times 10^{5} \pm 5.77 \times 10^{4}$ & $4.10 \times 10^{5} \pm 1.73 \times 10^{4}$ & $3.10 \times 10^{6} \pm 1.23 \times 10^{6}$ & $1.00 \times 10^{6} \pm 3.61 \times 10^{5^{*}}$ \\
\hline & & W & $5.03 \times 10^{5} \pm 9.50 \times 10^{4}$ & $8.60 \times 10^{6} \pm 3.49 \times 10^{6}$ & $1.12 \times 10^{8} \pm 1.50 \times 10^{7}$ & $1.10 \times 10^{7} \pm 2.65 \times 10^{6}$ \\
\hline & $2 \mathrm{mg} / \mathrm{mL}$ & S & $5.20 \times 10^{5} \pm 3.47 \times 10^{4}$ & $7.53 \times 10^{6} \pm 7.23 \times 10^{5}$ & $1.68 \times 10^{8} \pm 6.43 \times 10^{6}$ & $2.57 \times 10^{5} \pm 9.29 \times 10^{4^{*}}$ \\
\hline & & $\mathrm{P}$ & $5.53 \times 10^{5} \pm 4.51 \times 10^{4}$ & $6.40 \times 10^{6} \pm 9.64 \times 10^{5}$ & $1.36 \times 10^{8} \pm 4.04 \times 10^{6}$ & $3.17 \times 10^{7} \pm 1.22 \times 10^{7^{*}}$ \\
\hline & Cont & & $4.36 \times 10^{5} \pm 1.21 \times 10^{5}$ & nd & nd & $7.83 \times 10^{6} \pm 3.01 \times 10^{6}$ \\
\hline \multirow{7}{*}{$\begin{array}{l}\text { Salmonella } \\
\text { Enteritidis }\end{array}$} & & W & $5.95 \times 10^{6} \pm 1.40 \times 10^{6}$ & $9.30 \times 10^{8} \pm 2.33 \times 10^{8}$ & $9.80 \times 10^{8} \pm 2.44 \times 10^{8}$ & $1.10 \times 10^{7} \pm 7.60 \times 10^{6}$ \\
\hline & $1 \mathrm{mg} / \mathrm{mL}$ & S & $5.90 \times 10^{6} \pm 6.00 \times 10^{5}$ & $8.37 \times 10^{8} \pm 1.10 \times 10^{8}$ & $6.83 \times 10^{8} \pm 5.23 \times 10^{8}$ & $2.17 \times 10^{6} \pm 5.69 \times 10^{5^{*}}$ \\
\hline & & $\mathrm{P}$ & $6.02 \times 10^{6} \pm 2.40 \times 10^{6}$ & $7.17 \times 10^{8} \pm 1.95 \times 10^{8}$ & $1.33 \times 10^{9} \pm 5.20 \times 10^{7}$ & $9.83 \times 10^{6} \pm 8.54 \times 10^{6}$ \\
\hline & & W & $4.30 \times 10^{6} \pm 1.04 \times 10^{6}$ & $5.10 \times 10^{8} \pm 7.94 \times 10^{7}$ & $7.87 \times 10^{8} \pm 6.35 \times 10^{7}$ & $3.56 \times 10^{7} \pm 2.70 \times 10^{7}$ \\
\hline & $2 \mathrm{mg} / \mathrm{mL}$ & S & $4.00 \times 10^{6} \pm 6.08 \times 10^{5}$ & $4.47 \times 10^{8} \pm 4.04 \times 10^{7}$ & $8.43 \times 10^{8} \pm 1.11 \times 10^{8}$ & $1.61 \times 10^{7} \pm 9.00 \times 10^{6}$ \\
\hline & & $\mathrm{P}$ & $4.87 \times 10^{6} \pm 1.08 \times 10^{6}$ & $8.90 \times 10^{8} \pm 2.01 \times 10^{8}$ & $7.23 \times 10^{8} \pm 5.51 \times 10^{7}$ & $2.57 \times 10^{6} \pm 2.62 \times 10^{6^{6}}$ \\
\hline & Cont & & $7.53 \times 10^{6} \pm 3.02 \times 10^{6}$ & nd & nd & $4.00 \times 10^{7} \pm 2.40 \times 10^{7}$ \\
\hline \multirow{7}{*}{$\begin{array}{l}\text { Salmonella } \\
\text { Typhimurium }\end{array}$} & & W & $4.70 \times 10^{6} \pm 7.94 \times 10^{5}$ & $4.50 \times 10^{8} \pm 2.21 \times 10^{8}$ & $9.90 \times 10^{8} \pm 2.65 \times 10^{7}$ & $3.80 \times 10^{8} \pm 2.65 \times 10^{7}$ \\
\hline & $1 \mathrm{mg} / \mathrm{mL}$ & S & $3.90 \times 10^{6} \pm 1.31 \times 10^{6}$ & $6.60 \times 10^{8} \pm 2.13 \times 10^{8}$ & $1.35 \times 10^{9} \pm 3.23 \times 10^{8}$ & $3.20 \times 10^{8} \pm 2.00 \times 10^{7}$ \\
\hline & & $\mathrm{P}$ & $4.57 \times 10^{6} \pm 1.82 \times 10^{6}$ & $5.27 \times 10^{8} \pm 1.03 \times 10^{8}$ & $7.57 \times 10^{8} \pm 1.60 \times 10^{8}$ & $2.27 \times 10^{8} \pm 6.43 \times 10^{7^{*}}$ \\
\hline & & W & $6.30 \times 10^{6} \pm 6.08 \times 10^{5}$ & $3.00 \times 10^{8} \pm 5.03 \times 10^{7}$ & $8.00 \times 10^{8} \pm 1.30 \times 10^{8}$ & $1.01 \times 10^{8} \pm 9.54 \times 10^{6^{*}}$ \\
\hline & $2 \mathrm{mg} / \mathrm{mL}$ & S & $5.50 \times 10^{6} \pm 6.08 \times 10^{5}$ & $3.23 \times 10^{8} \pm 4.04 \times 10^{7}$ & $8.03 \times 10^{8} \pm 8.74 \times 10^{7}$ & $3.63 \times 10^{8} \pm 1.14 \times 10^{8}$ \\
\hline & & $\mathrm{P}$ & $6.50 \times 10^{6} \pm 1.80 \times 10^{6}$ & $3.40 \times 10^{8} \pm 5.20 \times 10^{7}$ & $6.33 \times 10^{8} \pm 3.51 \times 10^{7}$ & $2.93 \times 10^{8} \pm 2.09 \times 10^{7}$ \\
\hline & Cont & & $6.90 \times 10^{6} \pm 1.10 \times 10^{6}$ & nd & nd & $3.80 \times 10^{8} \pm 7.21 \times 10^{7}$ \\
\hline \multirow{7}{*}{$\begin{array}{l}\text { Lactobacillus } \\
\text { rhamnosus }\end{array}$} & & W & $1.10 \times 10^{7} \pm 2.00 \times 10^{6}$ & $1.27 \times 10^{8} \pm 6.93 \times 10^{7}$ & $6.85 \times 10^{8} \pm 5.07 \times 10^{7}$ & $7.33 \times 10^{7} \pm 2.52 \times 10^{7}$ \\
\hline & $1 \mathrm{mg} / \mathrm{mL}$ & S & $9.00 \times 10^{6} \pm 2.65 \times 10^{6}$ & $9.20 \times 10^{7} \pm 3.70 \times 10^{7}$ & $6.99 \times 10^{8} \pm 5.33 \times 10^{7}$ & $8.33 \times 10^{7} \pm 1.53 \times 10^{7}$ \\
\hline & & $\mathrm{P}$ & $1.13 \times 10^{7} \pm 3.21 \times 10^{6}$ & $6.37 \times 10^{7} \pm 3.51 \times 10^{7}$ & $6.60 \times 10^{8} \pm 4.00 \times 10^{7}$ & $1.96 \times 10^{8} \pm 4.51 \times 10^{7}$ \\
\hline & & W & $1.27 \times 10^{7} \pm 8.50 \times 10^{5^{*}}$ & $1.20 \times 10^{8} \pm 9.50 \times 10^{6}$ & $7.23 \times 10^{8} \pm 1.63 \times 10^{8}$ & $4.00 \times 10^{7} \pm 2.00 \times 10^{6^{*}}$ \\
\hline & $2 \mathrm{mg} / \mathrm{mL}$ & S & $1.42 \times 10^{7} \pm 2.33 \times 10^{6^{*}}$ & $1.50 \times 10^{8} \pm 3.55 \times 10^{7}$ & $8.83 \times 10^{8} \pm 5.51 \times 10^{7}$ & $3.87 \times 10^{7} \pm 6.03 \times 10^{6^{*}}$ \\
\hline & & $\mathrm{P}$ & $1.57 \times 10^{7} \pm 2.16 \times 10^{6}$ & $1.23 \times 10^{8} \pm 1.57 \times 10^{7}$ & $1.01 \times 10^{9} \pm 7.00 \times 10^{7}$ & $3.97 \times 10^{7} \pm 1.16 \times 10^{7^{*}}$ \\
\hline & Cont & & $1.73 \times 10^{7} \pm 1.53 \times 10^{7}$ & nd & nd & $2.17 \times 10^{8} \pm 7.64 \times 10^{7}$ \\
\hline
\end{tabular}

EHEC - Enterohemorrhagic E. coli; $\mathrm{W}$ - raspberry seedless pomace preparation; S - seed preparation; $\mathrm{P}$ - native raspberry pomace preparation; nd - not determined; *significant difference $(\mathrm{p}<0.05)$ compared to control. 
TABLE 3. Count of the pathogenic bacteria in the co-culture with L. rhamnosus (cfu/mL).

\begin{tabular}{|c|c|c|c|c|c|c|}
\hline \multirow{2}{*}{ Microorganism } & \multirow{2}{*}{$\begin{array}{l}\text { Culture } \\
\text { conditions }\end{array}$} & \multicolumn{5}{|c|}{ Incubation time (h) } \\
\hline & & 0 & 15 & 18 & 21 & 24 \\
\hline \multirow{2}{*}{ EHEC } & Co-culture & $4.25 \times 10^{6} \pm 3.51 \times 10^{5}$ & $2.40 \times 10^{8} \pm 4.65 \times 10^{7}$ & $2.18 \times 10^{8} \pm 7.21 \times 10^{6}$ & $2.60 \times 10^{8} \pm 3.46 \times 10^{7}$ & $1.73 \times 10^{8} \pm 1.89 \times 10^{7^{7}}$ \\
\hline & Control & $4.00 \times 10^{6} \pm 2.58 \times 10^{6}$ & nd & nd & nd & $3.00 \times 10^{8} \pm 4.00 \times 10^{7}$ \\
\hline \multirow{2}{*}{$\begin{array}{l}\text { Listeria } \\
\text { monocytogenes }\end{array}$} & Co-culture & $7.00 \times 10^{5} \pm 2.00 \times 10^{5}$ & $1.27 \times 10^{7} \pm 3.05 \times 10^{6}$ & $7.27 \times 10^{6} \pm 1.11 \times 10^{6}$ & $6.20 \times 10^{5} \pm 1.01 \times 10^{5}$ & $1.33 \times 10^{3} \pm 2.89 \times 10^{2^{2}}$ \\
\hline & Control & $5.67 \times 10^{5} \pm 1.15 \times 10^{5}$ & nd & nd & nd & $4.03 \times 10^{8} \pm 4.17 \times 10^{7}$ \\
\hline \multirow{2}{*}{$\begin{array}{l}\text { Salmonella } \\
\text { Enteritidis }\end{array}$} & Co-culture & $4.00 \times 10^{6} \pm 5.29 \times 10^{5}$ & $2.33 \times 10^{7} \pm 1.53 \times 10^{6}$ & $1.53 \times 10^{5} \pm 5.77 \times 10^{3}$ & $9.77 \times 10^{3} \pm 3.21 \times 10^{2}$ & $\mathrm{nf}^{*}$ \\
\hline & Control & $3,63 \times 10^{6} \pm 3.51 \times 10^{5}$ & nd & nd & nd & $3.77 \times 10^{8} \pm 3.79 \times 10^{7}$ \\
\hline \multirow{2}{*}{$\begin{array}{l}\text { Salmonella } \\
\text { Typhimurium }\end{array}$} & Co-culture & $7.47 \times 10^{6} \pm 1.07 \times 10^{6}$ & $3.10 \times 10^{8} \pm 4.00 \times 10^{7}$ & $4.53 \times 10^{7} \pm 1.53 \times 10^{6}$ & $3.70 \times 10^{4} \pm 8.88 \times 10^{3}$ & $\mathrm{nf}^{*}$ \\
\hline & Control & $6.80 \times 10^{6} \pm 1.06 \times 10^{6}$ & nd & nd & nd & $6.37 \times 10^{8} \pm 6.03 \times 10^{7}$ \\
\hline
\end{tabular}

EHEC - Enterohemorrhagic E. coli; nd - not determined; nf - not found; *significant difference ( $<<0.05)$ compared to control.

Even though growth inhibition of pathogenic bacteria is a desirable result of the applied raspberry preparations, an opposite effect is expected towards probiotic LAB strains. Nohynek et al. [2006] observed no antagonistic action of raspberry extracts on probiotic $L$. rhamnosus strains. In the study by Puupponen-Pimiä et al. [2001], Lactobacillus strains in the liquid culture were not affected by raspberry extracts at low concentrations $(1 \pm 1 \mathrm{mg} / \mathrm{mL})$. However, the growth of these bacteria was inhibited, when a five times higher concentration of raspberry extracts was used. The present research showed no antimicrobial effect of the $1 \mathrm{mg} / \mathrm{mL}$ raspberry preparation dose on L. rhamnosus growth in the liquid culture. On the other hand, bacteria counts were significantly lower for all combinations of raspberry preparations (concentration $2 \mathrm{mg} / \mathrm{mL}$ ) with L. rhamnosus compared to the control (Table 2).

The co-culture of probiotic lactobacilli and enteric pathogens is a laboratory method widely used to assess relationships between microorganisms tested. Chen et al. [2019] reported a significant growth inhibition of $E$. coli after 48-h co-culture with lactobacilli. A probiotic combination of $L$. acidophilus and $L$. rhamnosus caused a complete elimination of $E$. coli after $12 \mathrm{~h}$ [Bertuccini et al., 2017]. The reduction in Salmonella Enterica number (from $8 \log _{10}$ to no viable) occurred between 8 and $16 \mathrm{~h}$ of co-culture with the two LAB strains [Adetoye et al., 2018]. Our research showed a high inhibitory effect of the probiotic Lactobacillus against Salmonella strains, resulting in the reduction of pathogen count below the inoculum level within $24 \mathrm{~h}$ (Table 3). After 24-h co-incubation, L. monocytogenes number decreased from the initial $7.00 \times 10^{5} \mathrm{cfu} / \mathrm{mL}$ to $1.33 \times 10^{3} \mathrm{cfu} / \mathrm{mL}$, while in the control pure culture it exceeded $10^{8} \mathrm{cfu} / \mathrm{mL}$ (Table 3). Although the concentration of enterohemorrhagic $E$. coli cells in the co-culture and control culture remained at the same level of $10^{8} \mathrm{cfu} / \mathrm{mL}$ during the final analysis, a significant inhibitory activity of $L$. rhamnosus against EHEC was reported (Table 3).

Although various mechanisms, including the production of bacteriocins and $\mathrm{H}_{2} \mathrm{O}_{2}$, are linked to pathogen growth inhibition by $\mathrm{LAB}$ probiotic strains, the acidification of the growth medium is suggested to be the crucial factor responsible for the co-culture reduction efficiency [Chen et al., 2019; Delley et al., 2015]. On the other hand, Shen et al. [2014] reported a weak effect of the medium $\mathrm{pH}$ on the antibacterial activity of blueberry ethanol extract. A weak correlation between berry juices acidity and their antimicrobial effect was also noted by Krisch et al. [2008].

TABLE 4. Count of Lactobacillus rhamnosus (cuf/mL) in the co-culture with the pathogenic bacteria and raspberry preparations in the concentration of $2.0 \mathrm{mg} / \mathrm{mL}$.

\begin{tabular}{|c|c|c|c|}
\hline \multirow{2}{*}{\multicolumn{2}{|c|}{ Co-culture conditions }} & \multicolumn{2}{|c|}{ Incubation time (h) } \\
\hline & & 0 & 24 \\
\hline \multicolumn{2}{|l|}{ EHEC } & $1.93 \times 10^{7} \pm 3.51 \times 10^{6^{*}}$ & $6.27 \times 10^{8} \pm 1.10 \times 10^{7}$ \\
\hline \multirow{3}{*}{$\begin{array}{l}\text { EHEC + } \\
\text { raspberry } \\
\text { preparations }\end{array}$} & W & $4.90 \times 10^{6} \pm 1.25 \times 10^{6^{*}}$ & $1.37 \times 10^{9} \pm 1.81 \times 10^{8^{*}}$ \\
\hline & S & $6.63 \times 10^{6} \pm 2.03 \times 10^{6}$ & $1.45 \times 10^{9} \pm 1.12 \times 10^{8^{*}}$ \\
\hline & $\mathrm{P}$ & $5.83 \times 10^{6} \pm 2.06 \times 10^{6^{*}}$ & $1.14 \times 10^{9} \pm 1.11 \times 10^{8^{*}}$ \\
\hline \multicolumn{2}{|c|}{ Listeria monocytogenes } & $1.00 \times 10^{7} \pm 1.70 \times 10^{6}$ & $6.23 \times 10^{8} \pm 4.15 \times 10^{7}$ \\
\hline \multirow{3}{*}{$\begin{array}{l}\text { Listeria } \\
\text { monocytogenes } \\
+ \text { raspberry } \\
\text { preparations }\end{array}$} & W & $4.53 \times 10^{6} \pm 2.54 \times 10^{6^{*}}$ & $8.77 \times 10^{8} \pm 1.00 \times 10^{8^{*}}$ \\
\hline & S & $9.07 \times 10^{6} \pm 2.57 \times 10^{6}$ & $8.33 \times 10^{8} \pm 1.27 \times 10^{8^{*}}$ \\
\hline & $\mathrm{P}$ & $3.40 \times 10^{6} \pm 5.29 \times 10^{5^{*}}$ & $1.01 \times 10^{9} \pm 8.14 \times 10^{7^{*}}$ \\
\hline \multicolumn{2}{|c|}{ Salmonella Enteritidis } & $2.20 \times 10^{7} \pm 7.00 \times 10^{6^{6}}$ & $7.33 \times 10^{8} \pm 7.51 \times 10^{6}$ \\
\hline \multirow{3}{*}{$\begin{array}{l}\text { Salmonella } \\
\text { Enteritidis } \\
\text { + raspberry } \\
\text { preparations }\end{array}$} & W & $1.10 \times 10^{7} \pm 9.50 \times 10^{5}$ & $1.30 \times 10^{9} \pm 1.27 \times 10^{8^{*}}$ \\
\hline & S & $8.10 \times 10^{6} \pm 1.71 \times 10^{6}$ & $1.02 \times 10^{9} \pm 6.43 \times 10^{7^{*}}$ \\
\hline & $\mathrm{P}$ & $3.63 \times 10^{6} \pm 1.19 \times 10^{6^{*}}$ & $1.08 \times 10^{9} \pm 1.77 \times 10^{7^{*}}$ \\
\hline \multicolumn{2}{|c|}{ Salmonella Typhimurium } & $1.23 \times 10^{7} \pm 6.03 \times 10^{6}$ & $6.03 \times 10^{8} \pm 1.20 \times 10^{7}$ \\
\hline \multirow{3}{*}{$\begin{array}{l}\text { Salmonella } \\
\text { Typhimurium } \\
\text { + raspberry } \\
\text { preparations }\end{array}$} & W & $5.77 \times 10^{6} \pm 1.08 \times 10^{6}$ & $9.60 \times 10^{8} \pm 1.64 \times 10^{8^{*}}$ \\
\hline & S & $4.93 \times 10^{6} \pm 2.10 \times 10^{6}$ & $9.77 \times 10^{8} \pm 6.11 \times 10^{7^{*}}$ \\
\hline & $\mathrm{P}$ & $5.23 \times 10^{6} \pm 2.44 \times 10^{6}$ & $1.29 \times 10^{9} \pm 6.51 \times 10^{7 *}$ \\
\hline \multicolumn{2}{|l|}{ Control } & $1.04 \times 10^{7} \pm 8.14 \times 10^{5}$ & $5.63 \times 10^{8} \pm 1.05 \times 10^{8}$ \\
\hline
\end{tabular}

EHEC - Enterohemorrhagic E. coli; W - raspberry seedless pomace preparation; $\mathrm{S}$ - seed preparation; $\mathrm{P}$ - native raspberry pomace preparation; *significant difference $(\mathrm{p}<0.05)$ compared to control. 

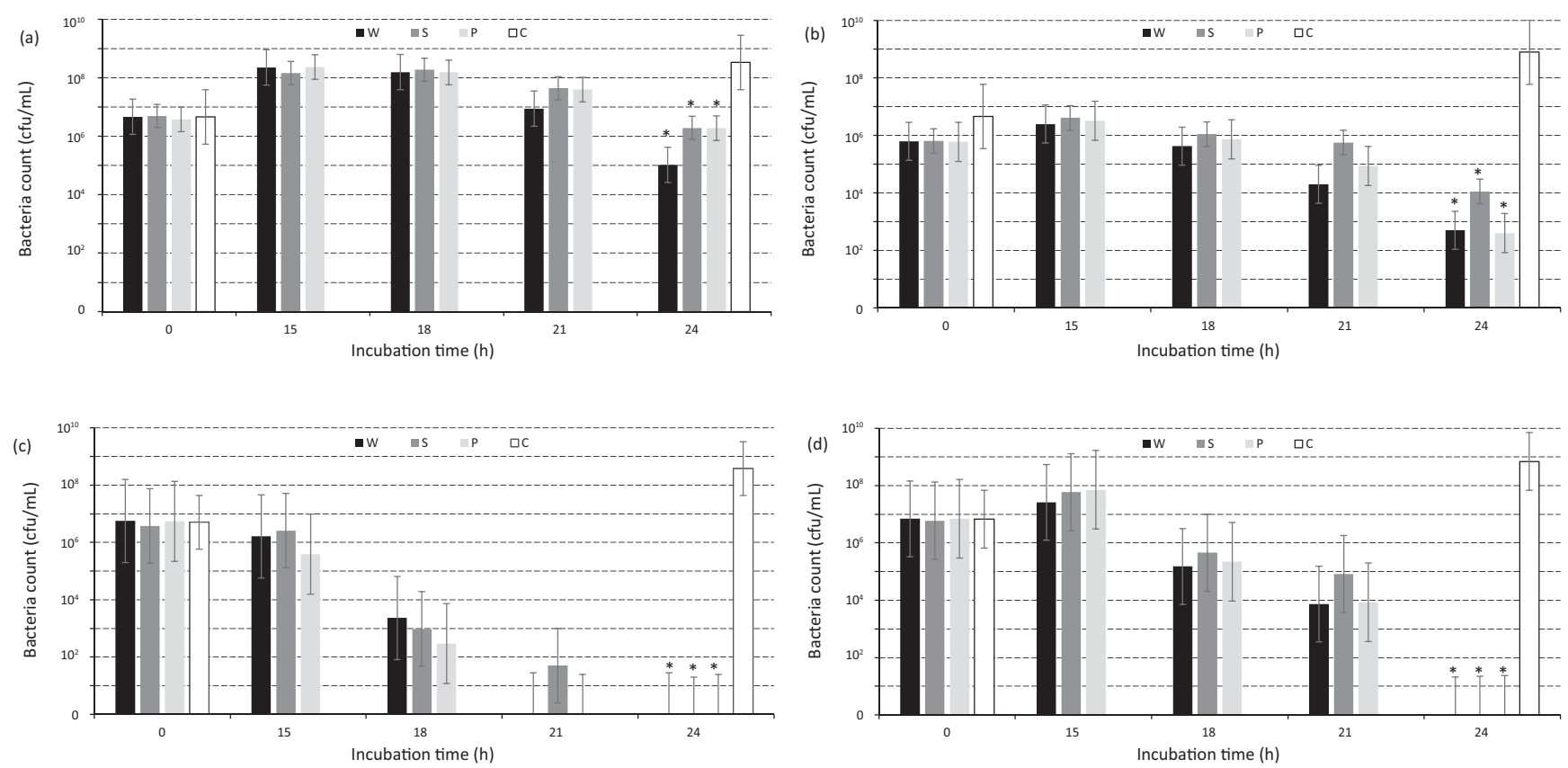

FIGURE 1. Count of the pathogenic bacteria (cuf $/ \mathrm{mL})$ in the co-culture with $L$. rhamnosus and raspberry seedless pomace, seeds and native pomace (W, S and P preparations, respectively) in the concertation of $2.0 \mathrm{mg} / \mathrm{mL}$; (a) Escherichia coli, (b) Listeria monocytogenes, (c) Salmonella Enteritidis, and (d) Salmonella Typhimurium.

*Significant difference $(\mathrm{p}<0.05)$ compared to control.

The co-culture with enteric pathogens did not influence the growth of lactobacilli during the 24-h incubation. Probiotic strain cell count was comparable to that observed in the control culture and approximated $10^{8} \mathrm{cfu} / \mathrm{mL}$. A significant increase in $L$. rhamnosus number was observed in all of the mixed cultures enriched with raspberry preparations. Their number after 24-h incubation ranged from $10^{8} \mathrm{cfu} / \mathrm{mL}$ to $10^{\circ} \mathrm{cfu} / \mathrm{mL}$ and exceeded the values obtained in the co-culture including bacterial strains only, regardless of preparation type (Table 4). A lack of the inhibitory effect of pathogenic bacteria on lactobacilli was also confirmed in the above-mentioned studies [Chen et al., 2019; Adetoye et al., 2018].

The enrichment of the pathogen-probiotic mixed culture with raspberry preparations resulted in the reduction of pathogen cell count (Figure 1). In most cases, the addition of raspberry preparations to the co-culture caused a greater reduction in pathogen populations, compared to cultures with Lactobacillus only. Similarly to the results obtained in the experiment with bacterial co-cultures not mixed with berry preparations, complete inactivation of the tested Salmonella strains was observed within in $24 \mathrm{~h}$ (Figure 1). Moreover, the complete elimination of Salmonella Enteritidis was reported after $21 \mathrm{~h}$ of incubation with $L$. rhamnosus mixed with $\mathrm{W}$ and $\mathrm{P}$ preparations. The concentration of $S$. Typhimurium cells in the mixed cultures decreased after $21 \mathrm{~h}$ from $10^{6} \mathrm{cfu} / \mathrm{mL}$ to $10^{3}-10^{4} \mathrm{cfu} / \mathrm{mL}$. L. monocytogenes proved less sensitive to L. rhamnosus and raspberry preparations; however, the reduction in cell number from $10^{5}$ to $10^{2} \mathrm{cfu} / \mathrm{mL}$ was found after $24 \mathrm{~h}$ of the co-culture with the addition of pomace $(\mathrm{P})$ and seedless pomace preparations (W). On the other hand, EHEC revealed the highest resistance to the mixed culture effect.
The results of the study showed no influence of the raspberry preparations type and chemical composition on their antimicrobial efficiency. The higher concentration of phenolics and ellagitannins in the seedless pomace preparation (W) did not result in its stronger inhibitory effect on enteric pathogens and Lactobacillus, compared to other raspberry preparations tested (S, P) (Table 2, 4 and Figure 1).

The results from the present study demonstrate that the combination of Lactobacilli and raspberry preparations was synergic against the pathogens tested. The idea of the coupled application of berry products and LAB or their metabolites was also examined in other studies. Terpou et al. [2019] used berries as an immobilization carrier of the probiotic lactobacilli in the functional frozen yogurt production, resulting in the improved product flavor and microbiological stability. In the study on the malolactic fermentation effect on the berry juice composition, Markkinen et al. [2019] found that fermentation by Lactobacillus plantarum decreased the content of hydroxycinnamic acids but not of anthocyanins in chokeberry. Finally, the high antimicrobial potential of natural formulations based on plant oils or extracts, and lactic acid against L. monocytogenes, E. coli, and $S$. Typhimurium was reported by Harich et al. [2018].

\section{CONCLUSIONS}

Our study showed no or low antibacterial effect of raspberry preparations against the bacteria tested. Although other researchers generally confirmed the inhibitory action of raspberry-based products on microorganisms, heterogeneous and contrary results were obtained. The differences in the antimicrobial potential of the tested raspberry products are probably 
caused by the composition and amount of active compounds in the tested materials, or susceptibility of the bacterial strains tested. The coupled use of the probiotic Lactobacillus strain and raspberry preparations resulted in the synergic inhibitory effect against enteric pathogens. The obtained results suggest the possibility of the combined use of probiotics and active substances found in berries as natural antimicrobial agents for the food industry in functional food production. However, due to the high unpredictability of the final effect of these factors on bacteria growth, further studies in this research area need to be continued and extended.

\section{CONFLICT OF INTERESTS}

Authors declare no conflict of interests.

\section{ORCID IDs}

J. Bauza-Kaszewska https://orcid.org/0000-0003-2972-6131

B. Fotschki https://orcid.org/0000-0002-9727-7481

A. Gugolek https://orcid.org/0000-0002-5360-9755

J. Juśkiewicz https://orcid.org/0000-0003-0068-5970

E. Karlińska https://orcid.org/0000-0002-7091-1278

M. Kosmala https://orcid.org/0000-0002-9018-3028

A. Ligocka https://orcid.org/0000-0002-7452-3213

E. Żary-Sikorska https://orcid.org/0000-0001-8140-3861

\section{REFERENCES}

1. Adetoye, A., Pinloche, E., Adeniyi, B. (2018). Characterization and anti-salmonella activities of lactic acid bacteria isolated from cattle faeces. BMC Microbiology, 18, art. no. 96.

https://doi.org/10.1186/s12866-018-1248-y

2. AOAC. (2007). Official Methods of Analysis of AOAC International. 18th ed. Washington: Association of Official Analytical Chemists.

3. Balasundram, N., Sundram, K., Samman, S. (2006). Phenolic compounds in plants and agri-industrial by-products: antioxidant activity, occurrence, and potential use. Food Chemistry, 99 , 191-203.

https://doi.org/10.1016/j.foodchem.2005.07.042

4. Baptista, R.C., Horita, C.N., Sant'Ana, A.S. (2020). Natural products with preservative properties for enhancing the microbiological safety and extending the shelf-life of seafood: a review. Food Research International, 127, art.no. 108762. https://doi.org/10.1016/j.foodres.2019.108762

5. Bertuccini, L., Russo, R., Iosi, F., Superti, F. (2017). Effects of Lactobacillus rhamnosus and Lactobacillus acidophilus on bacterial vaginal pathogens. International Journal of Immunopathology and Pharmacology, 30, 163-167.

https://doi.org/10.1177/0394632017697987

6. Burton-Freeman, B.M., Sandhu, A.K., Edirisinghe, I. (2016). Red raspberries and their bioactive polyphenols: Cardiometabolic and neuronal health links. Advances in Nutrition, 7, 44-65. https://doi.org/10.3945/an.115.009639

7. Chen, C.C., Lai, C.C., Huang, H.L., Huang, W.Y., Toh, H.S., Weng, T.C., Chuang, Y.C., Lu, Y.C., Tang, H.J. (2019). Antimicrobial activity of Lactobacillus species against carbapenem-resistant Enterobacteriaceae. Frontiers in Microbiology, 10, art. no. 789. https://doi.org/10.3389/fmicb.2019.00789
8. Coultate, T., Ed. (2016). Food: The Chemistry of its Components. $6^{\text {th }}$ edition. Royal Society of Chemistry, Cambridge, UK. p. 250.

9. Četojević-Simin, D.D., Velićanski, A.S., Cvetković, D.D., Markov, S.L., Ćetković, G.S., Šaponjac, V.T.T., Vulić, J.J., Čanadanović-Brunet, J.M., Djilaset, S.M. (2015). Bioactivity of Meeker and Willamette raspberry (Rubus idaeus L.) pomace extracts. Food Chemistry, 166, 407-413.

https://doi.org/10.1016/j.foodchem.2014.06.063

10. Das, Q., Islam, M.R., Marcone, M.F., Warriner, K., Diarra, M.S. (2017). Potential of berry extracts to control foodborne pathogens. Food Control, 73, 650-662.

https://doi.org/10.1016/j.foodcont.2016.09.019

11. Delley, M., Bruttin, A., Richard, M., Affolter, M., Rezzonico, E., Brück, W.M. (2015). In vitro activity of commercial probiotic Lactobacillus strains against uropathogenic Escherichia coli. FEMS Microbiology Letters, 362(13), art. no. fnv096. https://doi.org/10.1093/femsle/fnv096

12. Fotschki, B., Juśkiewicz, J., Jurgoński, A., Rigby, N., Sójka, M., Kołodziejczyk, K., Mackie, A., Zduńczyk, Z. (2017). Raspberry pomace alters cecal microbial activity and reduces secondary bile acids in rats fed a high-fat diet. Journal of Nutritional Biochemistry, 46, 13-20.

https://doi.org/10.1016/j.jnutbio.2017.03.004

13. Grumezescu, A. (Ed.) (2016). Nutrient Delivery, $1^{\text {st }}$ edition. Academic Press, London, UK. p. 543.

14. Harich, M., Maherani, B., Salmieri, S., Lacroix, M. (2018). Evaluation of antibacterial activity of two natural bio-preservatives formulations on freshness and sensory quality of ready to eat (RTE) foods. Food Control, 85, 29-41.

https://doi.org/10.1016/j.foodcont.2017.09.018

15. Heinonen, M. (2007). Antioxidant activity and antimicrobial effect of berry phenolics - a Finnish perspective. Molecular Nutrition and Food Research, 51, 684-691.

https://doi.org/10.1002/mnfr.200700006

16. Jimenez-Garcia, S.N., Guevara-Gonzalez, R.G., Miranda-Lopez, R., Feregrino-Perez, A.A., Torres-Pacheco, I., Vazquez-Cruz, M.A. (2013). Functional properties and quality characteristics of bioactive compounds in berries: Biochemistry, biotechnology, and genomics. Food Research International, 54(1), 1195-1207. https://doi.org/10.1016/j.foodres.2012.11.004

17. Klimczak, E., Rozpara, E., Król, B. (2011). Distribution of ellagitannins in juice, flesh, and achenes as additional criterion for optimal utilization of strawberries. Żywność. Nauka. Technologia. Jakość, 6, 142-154.

18. Klewicka, E., Sójka, M., Klewicki, R., Kołodziejczyk, K., Lipińska, L., Nowak, A. (2016). Ellagitannins from raspberry (Rubus idaeus L.) fruit as natural inhibitors of Geotrichum candidum. Molecules, 21 (7), art. no. 908 . https://doi.org/10.3390/molecules21070908

19. Krisch, J., Galgóczy, L., Tölgyesi, M., Papp, T., Vágvölgyi, C. (2008). Effect of fruit juices and pomace extracts on the growth of Gram-positive and Gram-negative bacteria. Acta Biologica Szegediensis, 52, 267-270.

20. Krstic, T., Suvajdzic, L., Stojanovic, S., Velhner, M., Milanov, D., Bojic, G., Ilić, N. (2014). Different antimicrobial effects of raspberry depending on the method of active components isolation. Food and Feed Research, 41, 125-130. https://doi.org/10.5937/FFR1402125K 
21. Lima, M.C., Paiva de Sousa, C., Fernandez-Prada, C., Harel, J., Dubreuil , J.D., de Souza, E.L. (2019). A review of the current evidence of fruit phenolic compounds as potential antimicrobials against pathogenic bacteria. Microbial Pathogenesis, 130, 259-270.

https://doi.org/10.1016/j.micpath.2019.03.025

22. Małecka, M., Rudzińska, M., Pachołek, B., Wąsowicz, E. (2003). The effect of raspberry, black currant and tomato seed extracts on oxyphytosterols formation in peanuts. Polish Journal of Food and Nutrition Sciences, 53, 49-53.

23. Markkinen, N., Laaksonen, O., Nahku, R., Kuldjarv, R., Yang, B. (2019). Impact of lactic acid fermentation on acids, sugars, and phenolic compounds in black chokeberry and sea buckthorn juices. Food Chemistry, 286, 204-215.

https://doi.org/10.1016/j.foodchem.2019.01.189

24. Negi, P.S. (2012). Plant extracts for the control of bacterial growth: efficacy, stability and safety issues for food application. International Journal of Food Microbiology, 156(1), 7-17. https://doi.org/10.1016/j.ijfoodmicro.2012.03.006

25. Nile, S.H., Park, S.W. (2014). Edible berries: bioactive components and their effect on human health. Nutrition, 30, 134-144. https://doi.org/10.1016/j.nut.2013.04.007

26. Nohynek, L.J., Alakomi, H.L., Kähkönen, M.P., Heinonen, M., Helander, I.M., Oksman-Caldentey, K.M., Puupponen-Pimiä, R.H. (2006). Berry phenolics: antimicrobial properties and mechanisms of action against severe human pathogens. Nutrition and Cancer, 54, 18-32.

https://doi.org/10.1207/s15327914nc5401_4

27. Pandey, A.K., Kumar, P., Singh, P., Tripathi, N.N., Bajpai, V.K. (2017). Essential oils: Sources of antimicrobials and food preservatives. Frontiers in Microbiology, 7, art.no. 2161. https://doi.org/10.3389/fmicb.2016.02161

28. Paredes-López, O., Cervantes-Ceja, M.L., Vigna-Pérez, M., Hernández-Pérez, T. (2010). Berries: improving human health and healthy aging, and promoting quality life - a review. Plant Foods for Human Nutrition, 65(3), 299-308. https://doi.org/10.1007/s11130-010-0177-1

29. Puupponen-Pimiä, R., Nohynek, L., Alakomi, H.L., Oksman-Caldentey, K.M. (2005a). Bioactive berry compounds - novel tools against human pathogens. Applied Microbiology and Biotechnology, 67, 8-18.

https://doi.org/10.1007/s00253-004-1817-x

30. Puupponen-Pimiä, R., Nohynek, L., Alakomi, H.L., Oksman-Caldentey, K.M. (2005b). The action of berry phenolics against human intestinal pathogens. Biofactors, 23, 243-251. https://doi.org/10.1002/biof.5520230410

31. Puupponen-Pimiä, R., Nohynek, L., Meier, C., Kähkönen, M., Heinonen, M., Hopia, A., Oksman-Caldentey, K.M. (2001). Antimicrobial properties of phenolic compounds from berries. Journal of Applied Microbiology, 90(4), 494-507. https://doi.org/10.1046/j.1365-2672.2001.01271.x

32. Rauha, J.P., Remes, S., Heinonen, M., Hopia, A., Kähkönen, M., Kujala, T., Pihlaja, K., Vuorela, H., Vuorela, P. (2000). Antimicro- bial effects of Finnish plant extracts containing flavonoids and other phenolic compounds. International Journal of Food Microbiology, 56(1), 3-12.

https://doi.org/10.1016/S0168-1605(00)00218-X

33. Salaheen, S., Jaiswal, E., Joo, J., Peng, M., Ho, R., OConnor, D., Adlerz, K., Aranda-Espinoza, J.H., Biswas, D. (2016). Bioactive extracts from berry byproducts on the pathogenicity of Salmonella Typhimurium. International Journal of Food Microbiology, 237, 128-135.

https://doi.org/10.1016/j.ijfoodmicro.2016.08.027

34. Schieber, A., Stintzing, F.C., Carle, R. (2001). By-products of plant food processing as a source of functional compounds recent developments. Trends in Food Science and Technology, 12, 401-413.

https://doi.org/10.1016/S0924-2244(02)00012-2

35. Shahidi, F. Alasalvar, C. (Eds.) (2016). Handbook of Functional Beverages and Human Health. CRC Press, Boca Raton, U.S., p. 114.

36. Shen, X., Sun, X., Xie, Q., Liu, H., Zhao, Y., Pan, Y., Hwang, C.A., Wu, V.C.H. (2014). Antimicrobial effect of blueberry (Vaccinium corymbosum L.) extracts against the growth of Listeria monocytogenes and Salmonella Enteritidis. Food Control, 35, 159-165.

https://doi.org/10.1016/j.foodcont.2013.06.040

37. Simmonds, M., Preedy, V.R. (Eds.) (2015). Nutritional Composition of Fruit Cultivars, $1^{\text {st }}$ edition. Academic Press, London, UK. pp. 717-729.

38. Stefanovic, O., Radojevic, I., Vasic, S., Comic, L. (2012). Antibacterial activity of naturally occurring compounds from selected plants. In V. Bobbarala (Ed.), Antimicrobial Agents, InTechOpen, ISBN 978-953-51-0723-1. https://doi.org/10.5772/33059

39. Stój, A., Malik, A., Targoński, Z. (2006). Comparative analysis of anthocyanin composition of juices obtained from selected species of beery fruits. Polish Journal of Food and Nutrition Sciences, 56(4), 401-407.

40. Terpou, A., Papadaki, A., Bosnea, L., Kanellaki, M., Kopsahelis, N. (2019). Novel frozen yogurt production fortified with sea buckthorn berries and probiotics. LWT - Food Science and Technology, 105, 242-249.

https://doi.org/10.1016/j.Iwt.2019.02.024

41. Velićanski, A., Cvetković, D.D., Markov, S. (2012). Screening of antibacterial activity of raspberry (Rubus idaeus L.) fruit and pomace extracts. Acta Periodica Technologica, 43, 305-313. https://doi.org/10.2298/APT1243305V

42. Vrhovsek, U., Giongo, L., Mattivi, F., Viola, R. (2009). Ellagitannin content in raspberry and blackberry cultivars grown in Trentino (Italy). Acta Horticulturae, 817, 85-90.

https://doi.org/10.17660/ActaHortic.2009.817.6

Submitted: 20 July 2020. Revised: 15 November 2020, 6 January and 27 January 2021. Accepted: 28 January 2021. Published on-line: 12 February 2021. 
